\title{
Violência doméstica de gênero e mediação de conflitos: a reatualização do conservadorismo
}

\author{
Domestic gender violence and conflict \\ mediation: the reatualization of conservatism
}

\author{
Natália Regina Parizotto \\ Assistente social (PUC-SP), mestre em Serviço Social (UERJ), assistente social da \\ Secretaria de Assistência Social de São José do Rio Preto (SP), Brasil. natalia.parizotto@gmail.com
}

Resumo: O presente artigo problematiza a utilização da modalidade jurídica da mediação de conflitos em processos cíveis relacionados à violência doméstica de gênero. Trata-se de uma pesquisa empírica e documental acerca da implementação da Lei Maria da Penha pelo Poder Judiciário - especialmente no que tange a reatualização do uso dessa modalidade jurídica. Relaciona a reestruturação produtiva com a autorreforma do Poder Judiciário.

Palavras-chave: Violência doméstica de gênero. Poder Judiciário. Mediação de Conflitos. Lei Maria da Penha.
Abstract: The present article problematizes the use of the legal modality of Conflict Mediation in civil cases related to domestic gender violence. This is an empirical and documentary research about the implementation of the Maria da Penha Law by the Judiciary Power - especially regarding the return to the utilization of this legal modality. Relates the productive restructuring with the self-reform of the Judiciary Power.

Keywords: Domestic gender violence. Judiciary Power. Conflict Mediation. Maria da Penha Law.

\section{Introdução}

$\mathrm{N}$

o presente artigo discutimos as implicações do uso da modalidade jurídica da Mediação de Conflitos em causas cíveis que têm, como

de gênero. Esta discussão faz parte de uma pesquisa mais ampla, fruto de nossa dissertação de mestrado, na qual discutimos a judicialização da Lei Maria da Penha na cidade de São Paulo (SP). 
A amostragem utilizada foi de cinco mulheres que instauraram um (ou mais) processos judiciais em virtude de violência doméstica de gênero que tenha resultado em uma ou mais audiências ocorridas na cidade de São Paulo (SP). Efetuamos entrevistas semiestruturadas e também o estudo de documentos processuais, disponibilizados pelos serviços onde estabelecemos a pesquisa, ou seja: o Centro de Referência da Mulher Casa Eliane de Grammont e a Regional Leste 2 da Defensoria Pública de São Paulo.

Acreditamos que essa amostragem teve a riqueza de ser composta por dois casos mais antigos e três casos mais recentes. Os processos de Susan e Mariana ${ }^{1}$ foram judicializado em 2010, quatro anos após a criação da Lei Maria da Penha (LMP). Já os processos de Elisa e Bette foram judicializados em 2015, quando a lei se aproximava de uma década de criação e implementação. A história de Diana localizou-se intermediariamente a esse processo. Seus primeiros boletins de ocorrência foram de 2011 e sua história se desenvolveu até o período de coleta da pesquisa (2016). Diana, Bette e Elisa carregam a urgência do momento em seus relatos. Sendo assim, acreditamos que as diferenças temporais puderam nos apontar as práticas jurídicas que têm se consolidado ao longo do tempo, assim como as novas tendências que têm despontado (ou sido reatualizadas).

Em um primeiro momento apresentaremos como a Lei Maria da Penha prevê a judicialização da violência doméstica a partir de um juizado híbrido. A seguir problematizaremos como ocorre o ajuizamento de causas sob a Lei Maria da Penha em São Paulo, especialmente no que tange à utilização dos Centros Judiciários de Solução de Conflitos e Cidadania. Por fim, traçaremos um paralelo entre a atual utilização da mediação de conflitos na esfera cível com a superada utilização da mediação de conflitos da esfera criminal (implementada anteriormente à promulgação da Lei Maria da Penha). Por fim, apontaremos algumas conclusões preliminares

1. Todos os nomes foram alterados para preservar a segurança, a privacidade e a intimidade das entrevistadas. Os nomes fictícios foram escolhidos a partir da obra Mulheres, da artista Carol Rossetti (2015). 
acerca da reatualização do uso dessa modalidade jurídica em casos de violência doméstica de gênero.

\section{A competência híbrida dos Juizados Especializados de Violência Doméstica e Familiar contra a Mulher}

A Lei Maria da Penha (LMP) é um marco de grandes inovações no enfrentamento à violência doméstica de gênero, especialmente por tratar este fenômeno a partir de suas particularidades. ${ }^{2}$ Para tanto, essa lei combina a atuação de uma multiplicidade de atores em torno de ações de prevenção e repressão à violência, assim como de assistência à mulher em situação de violência.

Com relação ao Poder Judiciário, a LMP indica a criação dos Juizados Especializados de Violência Doméstica e Familiar contra a Mulher (JVD). ${ }^{3}$ Esses juizados tratariam das ações criminais, assim como as ações cíveis que tivessem, como causa de seu pedido, eventos concernentes à violência doméstica de gênero. Seriam exemplos cíveis dessas causas: separação, divórcio, reconhecimento e dissolução de união estável, fixação de guarda e pensão alimentícia etc. Essa disposição garante que um juiz conheça amplamente um caso e possa arbitrar de maneira coerente acerca das diversas questões que circunscrevem um evento de violência doméstica de gênero. Só constituiriam uma exceção a essa regra os crimes dolosos contra a vida

2. Consideramos que violência doméstica de gênero recorrentemente apresenta as seguintes particularidades: ser uma violência praticada por alguém com quem se guarda laços de afetividade, com frequência cotidiana, naturalizada, constituída de pequenos eventos, gerar perdas patrimoniais para a mulher, organizada sob o ciclo da violência, a vítima apresenta confusão de discurso, sente-se culpabilizada, isolada, responsável por cuidar do homem autor de violência - que geralmente avalia padecer algum traço de doença e/ou anomalia (Parizotto, 2016).

3. “Art. 14. Os Juizados de Violência Doméstica e Familiar contra a Mulher, órgãos da Justiça Ordinária com competência civel e criminal, poderão ser criados pela União, no Distrito Federal e nos territórios, e pelos estados, para o processo, o julgamento e a execução das causas decorrentes da prática de violência doméstica e familiar contra a mulher" (Brasil, 2006, grifos nossos). 
que exigiriam a atuação de uma vara especializada. Segundo o Observe (2010, p. 88):

Ao estabelecer esta conexão entre os litígios, a legislação visa permitir que o mesmo juiz que julga os pedidos de medidas protetivas — quando poderão ser deferidos pedidos de separação conjugal, guarda de filhos, ações de alimentos e medidas de proteção do patrimônio da mulher-vítima - leve em conta estas informações na apreciação da causa criminal, propiciando-lhe uma compreensão ampliada sobre o complexo cenário da violência que é praticada contra as mulheres no contexto das relações domésticas e familiares.

$\mathrm{Na}$ esteira desse pensamento, acreditamos que é preciso atuar para fazer cessar a violência (o que em geral é obtido na esfera criminal, especialmente através das medidas protetivas de urgência), mas é através das decisões firmadas na esfera cível que se sustenta o rompimento com um cotidiano doméstico de violência. Uma das entrevistadas, por exemplo, relatou que desejava muito mais a fixação da pensão alimentícia para seus filhos do que a condenação de seu ex-companheiro por ameaça e agressão. A dificuldade de conseguir um emprego tendo três filhos (duas meninas ainda pequenas) era o maior impeditivo para que ela conseguisse sustentar um lar sem o ex-companheiro que a agredia, fazendo da pensão alimentícia um elemento determinante em sua nova vida.

Para os defensores dos JVDs híbridos - tendência à qual nos filiamos —, discutir o enfrentamento à violência doméstica de gênero a partir de suas particularidades significa pensar os aspectos cíveis imbricados nos aspectos criminais. É preciso reconhecer uma desigualdade instalada nas relações de gênero entre homens e mulheres, o que, portanto, não coaduna com a igualdade geralmente presumida entre as partes em uma audiência cível.

Sendo assim, concordamos com a disposição da LMP sobre a criação dos JVD como juizados híbridos, pois compreendemos que, desta forma, o Poder Judiciário atenderia mais coerentemente as particularidades da violência doméstica, além de diminuir a quantidade de audiências (o que 
garantiria maior celeridade, menor exposição da intimidade das mulheres e menos reencontros com os seus ex-maridos/companheiros em audiências). Tal fato, consequentemente, reduziria a rota crítica $^{4}$ percorrida pelas mulheres em situação de violência.

Porém a pesquisa de campo demonstrou-nos que a competência híbrida não é uma realidade dos JVDs de São Paulo. Todos os processos criminais analisados para este estudo correram em JVDs, e os processos cíveis correram em Varas de Família ou Centros Judiciários de Solução de Conflitos e Cidadania. Segundo o relatório elaborado pelo Observe (2010, p. 89-90) até 2010, Belém do Pará era o único estado com um JVD efetivamente híbrido $^{5}$ devido à existência de uma lei estadual que permitiu a modificação da organização judiciária do estado. Por este exemplo, podemos observar que apesar dos entraves institucionais para a estruturação de JVDs híbridos, é possível fazê-lo.

\section{A operacionalização da Lei Maria da Penha na esfera cível}

O Código Civil (Brasil, 2002) presume, em seu texto, a igualdade de condições entre as partes de um processo. Sendo assim, no antigo Código de Processo Civil, ${ }^{6}$ a conciliação surgia como uma forma jurídica prevista no artigo 125 , inciso $\mathrm{IV}^{7}$ informando que deveria haver a proposta de conciliação

\footnotetext{
4. Segundo a PMSP (2011, p. 21): “A rota crítica refere-se ao caminho que a mulher percorre na tentativa de encontrar uma resposta do Estado e das redes sociais frente à situação de violência. Essa trajetória caracteriza-se por idas e vindas, círculos que fazem com que o mesmo caminho seja repetido sem resultar em soluções, levando ao desgaste emocional e à revitimização".

5. "Belém do Pará possui as únicas Varas de Violência Doméstica e Familiar contra a Mulher com competência ampla para conhecimento e julgamento de todas as ocorrências de violência contra as mulheres, desde as contravenções penais até os homicídios, e também aquelas de natureza cível. Isto foi possível porque, ao contrário do que se verifica em outros estados, uma lei estadual modificou a Organização Judiciária, criando uma nova Vara que tem competência de júri e atua exclusivamente para aplicação da Lei Maria da Penha com competência híbrida nas causas cíveis para todos os processos de família e criminais" (Observe, 2010, p. 89-90).

6. Vigente até fevereiro de 2016.

7. “Art. 125.IV - Tentar, a qualquer tempo, conciliar as partes” (Brasil, 1973).
} 
para todas as demandas judiciais. Os artigos 447, 448 e $449^{8}$ instituíam a conciliação como fase preliminar à audiência de instrução e julgamento, sendo que o termo de acordo homologado pelo juiz adquiriria valor de sentença.

O que observamos nos casos estudados menos recentes foi a constituição de audiências cíveis na Vara de Família, nas quais o juiz tentou encontrar uma solução para o conflito entre as partes, mas na inobservância desta, procedeu então para a instrução (oitiva das partes, testemunhas, análise de documentação) e julgamento. As audiências pela divisão de bens, fixação de pensão alimentícia e guarda dos filhos apresentaram as tensões entre o casal em desavença, de forma que a presença do juiz mostrou-se essencial para que fosse possível alcançar alguma decisão.

No entanto, Bette, que mais recentemente havia iniciado um processo de ordem cível (fixação de alimentos), teve seu processo designado ao Cejusc — despontando uma nova tendência do TJ/SP.

Em 2010, o Conselho Nacional de Justiça9 aprovou a Resolução n. 125 com o objetivo de impulsionar e uniformizar os métodos consensuais de solução de conflitos. A partir de sua publicação, os Tribunais de Justiça tiveram até doze meses para implementar os Cejusc - Centros Judiciários de Solução de Conflitos e Cidadania onde deveriam ocorrer as sessões de conciliação e mediação. ${ }^{10}$

8. “Art. 447. Quando o litígio versar sobre direitos patrimoniais de caráter privado, o juiz, de ofício, determinará o comparecimento das partes ao início da audiência de instrução e julgamento. Parágrafo único. Em causas relativas à família, terá lugar igualmente a conciliação, nos casos e para os fins em que a lei consente a transação. Art. 448. Antes de iniciar a instrução, o juiz tentará conciliar as partes. Chegando a acordo, o juiz mandará tomá-lo por termo. Art. 449. O termo de conciliação, assinado pelas partes e homologado pelo juiz, terá valor de sentença" (Brasil, 1973).

9. "Criado pela Emenda Constitucional n. 45, o Conselho Nacional de Justiça atua como órgão central do sistema judicial brasileiro e, como tal, destina-se à reformulação do Poder Judiciário por meio de ações diversas que compreendem planejamento, coordenação e controle administrativo que permitem o aperfeiçoamento da prestação jurisdicional" (CNJ, 2010, p. 7).

10. Na Resolução n. 125 do CNJ as palavras “conciliação e mediação" são utilizadas juntas sem discriminação do que exatamente caberia a cada uma delas. No site do CNJ, encontramos a seguinte explicação: "a mediação é uma forma de solução de conflitos na qual uma terceira pessoa, neutra e imparcial, facilita o diálogo entre as partes, para que elas construam, com autonomia e solidariedade, a melhor solução para o problema. Em regra, é utilizada em conflitos multidimensionais, ou complexos. [...]. A conciliação é um 
Em 2015, foi aprovado o novo Código de Processo Civil — Lei n. 13.105 - e também a Lei de Mediação, n. 13.140/2015. O novo CPC traz regras que privilegiam a conciliação entre as partes enquanto forma de solução dos conflitos, ${ }^{11}$ tendo um capítulo especificamente a seu respeito. A partir de março de 2016, após a apresentação de uma petição inicial cível por uma das partes e antes da resposta da outra parte, ocorrerá uma audiência de conciliação ou mediação, conforme disposto no artigo $334^{12}$ do novo CPC.

A audiência de conciliação ou mediação não é obrigatória, ${ }^{13}$ não prescinde da presença dos advogados das partes e poderá tomar mais de uma sessão. Também é possível que essa forma de audiência aconteça eletronicamente. ${ }^{14}$ Quando acontecer presencialmente, é esperado um tempo médio de vinte minutos de duração. ${ }^{15}$ Todo o processo de mediação judicial deverá ser concluído em até sessenta dias, contados a partir da primeira sessão, salvo quando as partes, de comum acordo, requisitarem sua prorrogação. Se não houver acordo, será designada audiência de instrução, durante a qual o juiz ainda poderá fazer nova tentativa de conciliação, assim como as partes também poderão solicitá-la.

Segundo a Resolução n. 125/2010, cabe ao CNJ auxiliar os tribunais na organização dos Cejuscs, sendo admitidas parcerias com entidades

método utilizado em conflitos mais simples, ou restritos, no qual o terceiro facilitador pode adotar uma posição mais ativa, porém neutra com relação ao conflito e imparcial. É um processo consensual breve, que busca uma efetiva harmonização social e a restauração, dentro dos limites possíveis, da relação social das partes (CNJ, 2015, s/n).

11. “Art $1^{\circ}[\ldots] \S 3^{\circ}$ A conciliação, a mediação e outros métodos de solução consensual de conflitos deverão ser estimulados por juízes, advogados, defensores públicos e membros do Ministério Público, inclusive no curso do processo judicial" (Brasil, 2015b).

12. "Art. 334. Se a petição inicial preencher os requisitos essenciais e não for o caso de improcedência liminar do pedido, o juiz designará audiência de conciliação ou de mediação com antecedência mínima de 30 (trinta) dias, devendo ser citado o réu com pelo menos 20 (vinte) dias de antecedência" (Brasil, 2015b).

13. “Art. 334. [...]. $4^{\circ} \mathrm{A}$ audiência não será realizada: I — se ambas as partes manifestarem, expressamente, desinteresse na composição consensual; II — quando não se admitir a autocomposição" (Brasil, 2015b).

14. "Art. 334. [...] $\S 7^{\circ} \mathrm{A}$ audiência de conciliação ou de mediação pode realizar-se por meio eletrônico, nos termos da lei (Brasil, 2015b).

15. “Art. 334. [...] § 12. A pauta das audiências de conciliação ou de mediação será organizada de modo a respeitar o intervalo mínimo de 20 (vinte) minutos entre o início de uma e o início da seguinte. 
públicas e privadas. Os conciliadores ou mediadores deverão fazer um curso de capacitação cujo conteúdo programático mínimo é determinado pelo CNJ. Esses cursos também poderão acontecer por meio de parcerias com entidades públicas ou privadas, além de instituições de ensino. Segundo a Lei de Mediação:

Art. 11. Poderá atuar como mediador judicial a pessoa capaz, graduada há pelo menos dois anos em curso de ensino superior de instituição reconhecida pelo Ministério da Educação e que tenha obtido capacitação em escola ou instituição de formação de mediadores, reconhecida pela Escola Nacional de Formação e Aperfeiçoamento de Magistrados - Enfam ou pelos tribunais, observados os requisitos mínimos estabelecidos pelo Conselho Nacional de Justiça em conjunto com o Ministério da Justiça. (Brasil, 2015b, grifos nossos)

Os Cejuscs contarão com um cadastro de mediadores e conciliadores devidamente capacitados. Quando os mesmos forem designados para atuar (atividade que poderá constituir trabalho voluntário), ${ }^{16}$ serão supervisionados pelo juiz coordenador do Cejusc a quem caberá a homologação dos acordos firmados. É interessante notar que apenas em caso de grande fluxo de atendimentos, o juiz coordenador poderá ser designado exclusivamente para a administração do Cejusc (Brasil, 2010).

Ao refletir sobre essa forma de audiência para os casos de violência doméstica, nossa primeira questão gira em torno de um elemento essencial à mediação: a igualdade entre as partes. Segundo a Lei de Mediação, seriam princípios norteadores dessa modalidade jurídica:

Art. $2^{\circ}$ A mediação será orientada pelos seguintes princípios:

I — imparcialidade do mediador;

II - isonomia entre as partes;

III — oralidade;

16. Art. 168. [...]§ $1^{\circ}$ A mediação e a conciliação podem ser realizadas como trabalho voluntário, observada a legislação pertinente e a regulamentação do tribunal (Brasil, 2015a). 
IV — informalidade;

V - autonomia da vontade das partes;

VI - busca do consenso;

VII - confidencialidade;

VIII — boa-fé. (Brasil, 2015b, grifos nossos)

Considerando que a violência de gênero de homens contra mulheres desenvolve-se a partir da disparidade de poder entre as partes (Saffioti, 2004), nossa hipótese é que esse modelo de solução de conflitos não atende às particularidades do fenômeno da violência doméstica de gênero.

\section{Violência Doméstica de Gênero e Mediação de Conflitos: uma retrospectiva comparativa}

Anteriormente à LMP, na década de 1990, o modelo conciliatório foi implementado para a solução de conflitos referentes aos crimes de violência doméstica de gênero. Sob a Lei n. 9.099/95, ${ }^{17}$ tais processos eram arbitrados nos Juizados Especiais Criminais (JECrim). À época, foi produzida muita literatura a respeito dessa experiência. Acreditamos que seria interessante traçar um paralelo entre a experiência de conciliação ou mediação criminal pregressa com a conciliação ou mediação cível atual.

17. Essa lei foi aprovada sob as premissas de contrarreforma do Estado (Behring, 2003). Nesse contexto aconteceu a autorreforma do Judiciário apoiada no Direito Penal Mínimo baseado na premissa da "mínima intervenção estatal com máximas garantias" (Azevedo, 2000, apud Izumino, 2004, p. 16). Essa reforma foi baseada nos princípios da celeridade, da economia processual, da informalização da justiça e da aplicação de penas alternativas - condizentes com a redução do Estado. A Lei n. 9.099/95 abrange os crimes de menor potencial ofensivo - crimes com pena máxima de um ano. A maioria dos crimes de violência doméstica de gênero era enquadrada como crime de menor potencial ofensivo — o que em si já desqualificava e banalizava esse tipo de violência. A partir dessa lei, os inquéritos policiais foram substituídos pelo termo circunstanciado: "uma espécie de inquérito simplificado com um resumo da ocorrência, acompanhado do laudo pericial, quando necessário, devendo tal termo ser remetido ao Juizado para realização de audiência de conciliação e julgamento" (Santos, 2001). A aplicação da Lei n. 9.099/95 foi alvo de constantes críticas do movimento feminista por uma série de fatores. O principal deles era o fato de essa não constituir uma legislação específica para a violência doméstica de gênero e, portanto, não atender as particularidades desse fenômeno. 
Debert e Oliveira (2007) relataram que os idealizadores do JECrim não haviam antecipado a quantidade de crimes de violência doméstica que esses juizados atenderiam. Nos JECrim, a maioria dos crimes arbitrados era de agressão física leve e ameaça (infrações recorrentes em crimes de violência doméstica), a maioria das vítimas era de mulheres e a maioria dos réus era de homens. Segundo as autoras "chamamos a atenção para o processo de feminização no JECrim, na medida em que as vítimas nessa instituição são mulheres e são vitimadas pelo fato de serem mulheres" (Debert e Oliveira, 2007, p. 314). No entanto, esses juizados não tinham nenhum preparo para atender essas demandas:

[...] o juiz no JECrim [...] não foi formado, não está preparado, nem se espera que ele esteja atento para a questão da "violência contra a mulher", mesmo que, na prática, esse tipo de criminalidade seja recorrente [...]. A percepção do juiz sobre o que é a família e sobre a importância do seu papel social orientam as decisões tomadas no JECrim. (Debert \& Oliveira, 2007, p. 331)

Quando observamos a Resolução n. 125/2010 (Brasil, 2010), especialmente qual a formação demandada dos conciliadores ou mediadores, nos resta a mesma dúvida sobre qual a competência dos mesmos para arbitrar casos de violência doméstica.

Resgatando os marcos legais que balizam o novo CPC, observamos neste a centralidade da conciliação ou mediação na condução das ações de família: "Art. 694. [...] todos os esforços serão empreendidos para a solução consensual da controvérsia, devendo o juiz dispor do auxílio de profissionais de outras áreas de conhecimento para a mediação e conciliação" (Brasil, 2015b). Nossa apreensão repousa-se no risco de os Cejuscs, assim como os JECrim, reproduzir as hierarquias inerentes às relações de gênero entre homens e mulheres ao tratá-los como indivíduos em igualdade, pois, como nos explicam Debert e Oliveira (2007, p. 329), “a conciliação do casal, [...] implica a dissolução da figura de vítima e de réu”. Esta conduta do Judiciário "reprivatizava" a violência doméstica, devolvendo o conflito ao âmbito 
familiar, onde "deveria ser solucionado". Debert e Oliveira (2007, p. 329) nos relatam esse exato exemplo nos JECrim:

Os operadores do direito, raramente, reconhecem que esse é um crime altamente sexualizado, no qual prevalecem a hierarquia de gênero e os preconceitos, ou seja, que a maioria das vítimas desses crimes são as mulheres e que são vitimadas simplesmente pelo fato de serem mulheres! Desse modo, a violência contra a mulher ganha novamente invisibilidade. "Eles é que devem resolver o problema deles. Só deveriam recorrer se fosse caso de lesão grave" - diz um juiz entrevistado considerando que um problema familiar deve ser resolvido em casa.

Nader (1994) nos auxiliou a refletir sobre a relação entre os modelos jurídicos que utilizamos e a estruturação de nossa cultura. Segundo a autora, a forma como lidamos com os conflitos sociais (ou a forma como negamos nossos conflitos) pode revelar processos de dominação em curso. De acordo com Nader (1994), a construção cultural em torno da apologia à harmonia seria uma estratégia para escamotear os conflitos fundamentais de uma sociedade, como os conflitos de classe, gênero e raça/etnia. Em vez de discutir como os conflitos estruturam-se, entram em voga as discussões sobre as relações interpessoais entre os indivíduos inscritos nesse conflito: "uma intolerância pelo conflito impregnou a cultura para evitar não as causas da discórdia, mas sua manifestação, e, a qualquer preço, criar consenso, homogeneidade, concórdia" (Nader, 1994, p. 21).

Ou seja, desta forma, a discussão em torno da "justiça" seria transferida para a retórica em torno da "harmonia" das relações interpessoais. Com o "desaparecimento do conflito", o que observamos é a naturalização e a legitimação das desigualdades vigentes e o que é mais grave: as disparidades de poder passam a operar nas conciliações em detrimento da parte desprivilegiada. Segundo Nader (1994, p. 27), "quando os casos que deveriam ser decididos judicialmente são negociados [...] [as] vantagens da negociação para os mais poderosos tornam-se óbvias". 
Segundo Nader (1994, p. 19), “o estilo harmônico, bem como as ideologias relacionadas são, possivelmente, acomodações internas à conquista e à dominação". Para alcançar tal conclusão, a autora retomou as colonizações, em que os países colonizadores impunham seu sistema jurídico aos povos colonizados sob a premissa de pacificá-los, o que significou silenciá-los e dominá-los. Conforme Nader (1994, p. 20), “é altamente provável que a ideologia da harmonia faça parte do sistema de controle hegemônico que se espalhou pelo mundo todo com a colonização política europeia e a evangelização cristã". Por essa razão a autora cunhou o termo "harmonia coercitiva", o que ela também denominou como uma "colonização mental".

Para compreender a influência recente da "harmonia coercitiva" nos Estados-nações modernos do tipo democrático ocidental, Nader (1994) recuperou o período da década de 1960 nos Estados Unidos marcado por importantes lutas em torno dos direitos civis, direitos ambientais, direitos das mulheres, direitos da população negra etc. Após esse período, teve início um momento histórico em que o discurso hegemônico acerca do Poder Judiciário evocava tribunais abarrotados e uma população "demasiado litigante", o que abriu margem para a expansão das Alternative Dispute Resolution (Resolução Alternativa de Disputa, tradução nossa). Se observarmos a cartilha produzida pelo Poder Judiciário acerca dos Cejuscs, reconhecemos argumentos similares:

Assunto corrente tem sido a crise do Poder Judiciário brasileiro, especialmente no que se refere à duração e ao custo do processo. Visando minimizar tais problemas e seguindo o caminho traçado por diversos países, a adoção dos Métodos Alternativos de Solução de Conflitos — Mascs — vem ganhando espaço no Brasil, tendo sido criadas nas últimas décadas inúmeras câmaras de conciliação, mediação e arbitragem, esta última já bastante utilizada nas relações empresariais. [...]

No âmbito do Poder Judiciário, diante da imensa quantidade de novos processos ajuizados diariamente, além dos milhares que aguardam julgamento, algumas medidas foram tomadas visando diminuir os efeitos da crise na solução de conflitos, estimulando a conciliação e a mediação. [...] 
O Cejusc [...] [contribui] assim para a disseminação da cultura da paz, que propicia maior rapidez na pacificação dos conflitos e produz resultados com acentuada utilidade social. (TJ/SP, s/d., p. 4-6; grifos nossos).

O discurso dessa cartilha está em convergência com as reflexões de Nader sobre a expansão das ADRs nos EUA: “o país passou de uma preocupação com a justiça para uma preocupação com a harmonia e a eficiência, de uma preocupação com a ética do certo e do errado para uma ética do tratamento, dos tribunais para a ADR" (1994, p. 20).

Se recordarmos processos socioeconômicos em marcha nesse período, relembramos que a década de 1970 marcou o fim dos "trinta anos gloriosos" que sucederam a Segunda Guerra Mundial e marcaram o início do neoliberalismo - uma resposta do capitalismo à sua crise estrutural, sua roupagem contemporânea, redesenhada de forma a garantir uma sobrevida a esse modo de produção (Antunes, 2003).

Reconhecemos essa tendência ganhando força no Brasil a partir da década de 1990, exatamente quando foi promulgada a Lei n. 9.099/95 e foram criados os JECrims.

É por essa razão que a criação dos LMPs é compreendida como a politização da justiça frente à violência doméstica. Significa requisitar a atuação de um Estado que historicamente omitiu-se de atuação na violência doméstica sob a falsa dicotomia entre as esferas pública e privada da vida social (Rocha, 2007, p. 31).

Sobre a referida "celeridade" dos métodos alternativos, gostaríamos de retomar a competência híbrida dos JVDs. Se as medidas protetivas fossem emitidas (sob sua característica não definitiva, vale lembrar) em 96 horas, ${ }^{18}$ as mulheres em situação de violência teriam determinadas: separação de corpos, fixação de pensão e guarda dos filhos, afastamento do homem autor de violência do lar (além de proibição de aproximação e contato), por exemplo,

18. Quarenta e oito horas para serem remetidas pela delegacia ao juiz e mais 48 horas para serem deferidas ou indeferidas. 
muito rapidamente. Quando ocorresse a audiência híbrida, o juiz poderia arbitrar amplamente sobre todos esses elementos e não seriam necessárias outras audiências. Dessa forma, alcançaríamos resultados rápidos sem que sequer fosse necessária a utilização do Cejusc.

Portanto, nos parece que a "morosidade" do Judiciário tem como um de seus fundamentos a maneira como os processos são conduzidos (divididos em cíveis e criminais) pelo próprio Judiciário. Parece-nos que a questão do tempo na verdade escamoteia uma questão mais profunda de valoração dos processos, isto é, quais processos merecem atenção e quais não deveriam ter sido judicializados ("deveriam ter sido resolvidos em casa”). Conforme a reflexão de Debert e Oliveira (2007, p. 330), "a lógica que orienta a conciliação nos juizados implica uma solução rápida, simples, informal e econômica para os casos que não deveriam ocupar espaço no Judiciário, tampouco o tempo de seus agentes".

Uma das nossas principais inquietações, no que tange o uso dessa modalidade jurídica, refere-se à segurança da mulher em situação de violência doméstica. Quando encontramos Bette para a presente pesquisa, ela aguardava para a segunda tentativa de audiência para a fixação de alimentos, sentada nos bancos do Cejusc. O local era uma sala de espera de tamanho médio, com muitos bancos justapostos. Quando seu ex-companheiro chegasse, ele teria que aguardar em um daqueles mesmos bancos. Não havia nenhum procedimento especial para casos onde existem medidas protetivas entre as partes, sendo que seu ex-companheiro deveria manter-se a cem metros dela. ${ }^{19}$ Como ele poderia fazê-lo nesse espaço, sem incorrer em infração penal? Como ela poderia ser protegida nesse espaço? Havia alguma proteção policial consciente de que ela havia sido jurada de morte por um homem que se aproximaria em breve? Ela receberia algum tipo de proteção ao deixar TJ/SP? Infelizmente, esse tipo de preocupação não é infundado, sendo corriqueiras as notícias de assassinatos posteriores a audiências dos noticiários

19. Por decisão proferida em medida protetiva. 
policiais. ${ }^{20}$ Por essa razão, inclusive, a LMP garante que as mulheres possam depor na ausência do homem autor de violência. Ou seja, faz-se necessária a criação de procedimentos que não reproduzam, muito menos potencializem, a violência doméstica de gênero.

Não atentar para os riscos que tais mulheres correm nesses espaços demonstra o despreparo e o descrédito que o Poder Judiciário majoritariamente reputa aos eventos desta ordem - o que pode, inclusive, colocar os funcionários desta instituição em risco. ${ }^{21}$

O ex-companheiro de Bette havia sido preso preventivamente por descumprimento de medidas protetivas de urgência. Quando foi designada a audiência de conciliação ou mediação no Cejusc para a fixação de guarda, não houve compartilhamento da informação sobre a prisão (na esfera criminal) com o Cejusc (na esfera cível) e seu ex-companheiro não pôde ser encontrado. Dessa forma, sua audiência pela segunda vez resultou infrutífera e sua angústia por não ter pensão alimentícia aumentou.

Parece-nos que os métodos alternativos de resolução de conflito vieram dar forma, no âmbito do Poder Judiciário, aos ditames neoliberais de contrarreforma do Estado. A demanda por eficiência no Poder Judiciário faz uníssono ao mesmo imperativo no circuito produtivo, marcado pela reestruturação produtiva. Tais traços são claramente reconhecíveis na estrutura do Cejusc: as audiências passam a ser simplificadas, de forma que possam ser conduzidas por mão de obra menos qualificada e, portanto, pior remunerada do que um juiz (quando não voluntária); as audiências passam a ter um tempo

20. A matéria foi denominada: "Homem matou a ex-companheira após a audiência de separação em Belo Horizonte, Minas Gerais. A mulher, que tinha uma medida protetiva contra o marido, foi estrangulada por ele". Disponível em: <http://noticias.band.uol.com.br/brasilurgente/video/2015/10/17/14367732/homem-mata-a-ex-mulher-apos-a-audiencia-de-separacao.html>. Acesso em: 18 jan. 2016.

21. Em março de 2016, um homem autor de violência invadiu o JVD do Butantã em São Paulo e manteve a juíza Tatiane Moreira Lima como sua refém durante vinte minutos. Nesse período, jogou um líquido inflamável em si e na juíza e passou a ameaçar acender um isqueiro. $\mathrm{O}$ homem obrigou a juíza a gravar um vídeo informando que o mesmo era inocente.

A matéria foi denominada: "Vídeo mostra homem ameaçando atear fogo em juíza no Fórum Butantã". Disponível em: <http://g1.globo.com/sao-paulo/noticia/2016/03/video-mostra-pm-negociando-libertacao-de-juiza-no-forum-butanta.html>. Acesso em: 15 maio 2016. 
reduzido (além de poderem acontecer eletronicamente), o que intensifica a "produtividade" do Cejusc; o juiz passa a gerenciar os conciliadores ou mediadores homologando todos os acordos de todas as audiências sob sua coordenação - o que aumenta concretamente a quantidade de "conflitos pacificados" sob sua atuação; além disso, é permitida a privatização de uma série de serviços necessários à estruturação dos Cejuscs, desde a formação dos conciliadores ou mediadores até a estruturação e o oferecimento do serviço à população. Como podemos observar, encontramos no Cejusc traços claros do neoliberalismo e do machismo no Estado.

\section{Considerações finais}

A partir da reflexão desenvolvida, acreditamos que a modalidade jurídica da conciliação ou mediação de conflitos reforça as desigualdades instaladas nas relações de gênero em contextos de violência doméstica. Entendemos que a utilização dessa modalidade jurídica, em meio a todas as demais demandas cíveis tratadas no Cejusc, oferece um trato superficial e insuficiente ao enfrentamento da violência doméstica de gênero. Tal fato põe a descoberto a banalização e a invisibilidade vigente dos crimes dessa natureza dentro do Poder Judiciário, não apenas pelo uso de instrumentos que não atendem às suas particularidades, mas também pelo risco que tais práticas podem gerar às mulheres (e também aos profissionais envolvidos). Conforme nos relembra Nader (1994, p. 20), a forma de estruturação do Poder Judiciário atende a uma ordem social dominante: "Os processos de disputa [...] refletem, mais exatamente, os processos de construção cultural que podem ser uma resposta à necessidade, um produto dos interesses preponderantes ou um resultado do conflito de classes".

Avaliamos que setores majoritários do Poder Judiciário, dessa forma, têm atuado tacitamente pela não implementação da LMP, evitando confrontar a violência doméstica de gênero devidamente, constituindo um verdadeiro retrocesso. Acreditamos que esse fato traduza, na esfera cível, uma nova 
ofensiva neoliberal e machista contra os direitos das mulheres, retomando práticas que deveriam ter sido superadas juridicamente pela implementação da LMP.

\section{Recebido em 7/1/18 - Aprovado em 23/2/18}

\section{Referências bibliográficas}

ANTUNES, Ricardo. Adeus ao trabalho? Ensaio sobre as metamorfoses e a centralidade do mundo do trabalho. São Paulo: Cortez, 2003.

BEHRING, Elaine Rossetti. Brasil em contra-reforma: desestruturação do Estado e perda de direitos. São Paulo: Cortez, 2003.

BRASIL. Lei n. 5.869, de 11 de janeiro de 1973. Código de processo civil. (Revogado pela Lei n. 13.105/ 2015. Disponível em: <http:/www.planalto.gov.br/ccivil_03/leis/ L5869.htm>. Acesso em: 22 maio 2015.

. Lei n. 9.099, 26 de setembro de 1995. Dispõe sobre os Juizados Especiais Cíveis e Criminais e dá outras providências. Diário Oficial da União, Brasília, DF. Disponível em: http://www.planalto.gov.br/ccivil_03/leis/19099.htm. Acesso em: 22 maio 2014.

. Lei n. 11.340 de 7 de agosto de 2006. Lei Maria da Penha. Diário Oficial da União, Brasília, DF. Disponível em: <http:/www.planalto.gov.br/ccivil_03/_ato20042006/2006/lei/111340.htm>. Acesso em: 26 maio 2014.

CONSELHO NACIONAL DE JUSTIÇA. Resolução CNJ n. 125 de 29 de novembro de 2010 (consolidada). Disponível em: <http://www.cnj.jus.br/busca-atosadm?documento=2579> . Acesso em: 10 set. 2017.

. Lei n. 13.105, de 16 de março de 2015a. Código de Processo Civil. Disponível em: <http://www.planalto.gov.br/ccivil_03/_Ato2015-2018/2015/Lei/L13105.htm>. Acesso em: 16 jan. 2016.

. Lei n. 13.140, de 26 de junho de 2015b. Dispõe sobre a mediação entre particulares como meio de solução de controvérsias e sobre a autocomposição de 
conflitos no âmbito da administração pública. Disponível em: <http://www.planalto. gov.br/ccivil_03/_Ato2015-2018/2015/Lei/L13140.htm>. Acesso em: 16 jan. 2016.

DEBERT, Guita Grin; OLIVEIRA, Marcella Beraldo de. Os modelos conciliatórios de solução de conflitos e a "violência doméstica". Cad. Pagu, Campinas, n. 29, p. 305-337, dez. 2007. Disponível em: <http://www.scielo.br/scielo.php?script=sci arttext\&pid $=$ S0104-83332007000200013\&lng=en\&nrm=iso $>$. Acesso em: 31 out. 2015.

DEFENSORIA PÚBLICA DE SÃO PAULO. Composição extrajudicial de conflitos. s/d. Disponível em: $<$ http://www.defensoria.sp.gov.br/dpesp/repositorio/0/documentos/ cam/Composi $\%$ C3\%A7\%C3\%A3o\%20Extrajudicial $\% 20 \mathrm{de} \% 20$ Conflitos.pdf $>$. Acesso em: 16 jan. 2016.

IZUMINO, Wania Pasinato. Justiça e violência contra a mulher: o papel do sistema Judiciário na solução dos conflitos de gênero. São Paulo: Annablume, Fapesp, 2004.

NADER, L. Harmonia coerciva: a economia política dos modelos jurídicos. Revista Brasileira de Ciências Sociais, São Paulo, ano 9, n. 29, p. 18-29, 1994. Disponível em: $<$ http://www.anpocs.org.br/portal/publicacoes/rbcs_00_26/rbcs26_02.htm >. Acesso em: 19 jan. 2016.

OBSERVE - OBSERVATÓRIO PELA APLICAÇÃO DA LEI MARIA DA PENHA. Condições para aplicação da Lei n. 11.340/06 (Lei Maria da Penha) nas Delegacias Especializadas de Atendimento à Mulher (DEAMS) e nos Juizados de Violência Doméstica e Familiar nas capitais e no Distrito Federal. Salvador, 2010. 233 p. Disponível em: <http://www.observatoriodegenero.gov.br/menu/publicacoes/outros-artigos-epublicacoes/relatorio-final-do-observatorio-de-monitoramento-da-lei-maria-da-penha $>$. Acesso em: 6 set. 2014.

PARIZOTTO, Natália R. Justiça: substantivo feminino?: considerações acerca da judicialização da Lei Maria da Penha. 2016. 355 f. Dissertação (Mestrado em Serviço Social) - Faculdade de Serviço Social, Universidade do Estado do Rio de Janeiro, Rio de Janeiro, 2016.

PREFEITURA DE SÃO PAULO. Guia de Procedimentos para o Atendimento à Mulheres em Situação de Violência nos Centros de Referência de Atendimento à Mulher e no Centro de Cidadania da Mulher. São Paulo, 2011. Disponível em: <telecentros. sp.gov.br/img/arquivos/Guia_de_Procedimentos_web.pdf $>$. Acesso em: 30 ago. 2014.

ROCHA, Lourdes de Maria Leitão Nunes. Casas-abrigo no enfrentamento da violência de gênero. São Paulo: Veras, 2007. 
ROSSETTI, Carol. Mulheres: retratos de respeito, amor-próprio, direitos e dignidade. São Paulo: Sextante/Gmt, 2015.

SAFFIOTI, Heleieth I. Gênero, patriarcado, violência. São Paulo: Fundação Perseu Abramo, 2004.

SANTOS, Cecília Macdowell. Delegacias da Mulher em São Paulo: percursos e percalços. 2001. Disponível em: <http://www.social.org.br/relatorio2001/relatorio023. htm>. Acesso em: 11 set. 2013.

TRIBUNAL DE JUSTIÇA DE SÃO PAULO. Cartilha Cejusc. Disponível em: <http:// www.tjsp.jus.br/download/secaodireitoprivado/cejusc/cartilhacejusc.pdf $>$. Acesso em: 22 jan. 2016. 